\title{
MORE ABOUT COMMERCIAL VEHICLES
}

\section{Dear Reader,}

The first International Engine Congress organised by ATZlive and VDI Wissensforum was a great success: 388 participants listened to 46 keynote speeches and papers as well as a panel discussion on the complete architecture of the engine, for both passenger car and commercial vehicle applications. The congress focused on the base engine, charge exchange, combustion, exhaust aftertreatment, engine management and thermal management. 20 exhibitors presented their portfolios to the interested participants.

A separate strand at the Baden-Baden conference was deliberately dedicated to the topic of commercial vehicles, and feedback has been extremely positive. For that reason, the International Engine Congress will include a self-contained commercial vehicle conference from 2015 onwards. This direct proximity to the "parent" congress will promote an exchange of information and opinions from the adjacent disciplines.

A high-ranking Scientific Advisory Board will continue to ensure that the papers at the commercial vehicle conference remain at the usual high standard. As Total Cost of Ownership is far more important for commercial vehicles than for passenger cars, the main focus will be on the topic of cutting $\mathrm{CO}_{2}$ emissions, in addition to the question of international fuel qualities. Minimising friction in the base engine and optimis- ing the combustion process will therefore definitely be among the issues that will determine this new commercial vehicle conference next year.

MTZ has set itself the goal of paying even greater attention to the commercial vehicle sector in the future. More specialist articles on this topic and the International Engine Congress are key components of this. Equally worthy of attention is our ATZextra on the IAA Commercial Vehicles in Hannover in September, which will be published jointly by ATZ and MTZ. We are already looking forward to receiving reports of your latest developments.

Best regards,

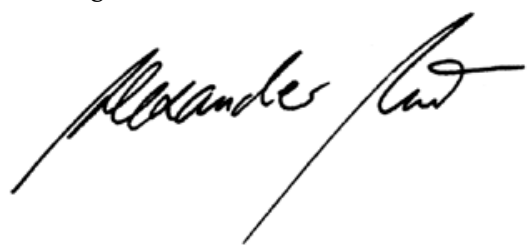

DR. ALEXANDER HEINTZEL, Editor in Chief Wiesbaden, 14 March 2014

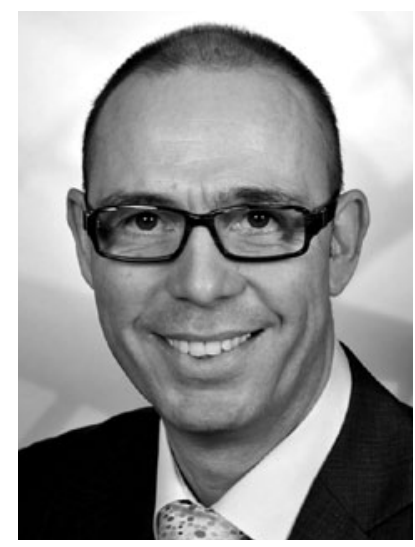

